\title{
Discurso jornalístico e política em tempos de pandemia: um debate necessário
}

\author{
Ivanise Hilbig de Andrade ${ }^{1}$ \\ Karolina Graciano Cardoso ${ }^{2}$ \\ Mirna Tonus ${ }^{3}$ \\ Raquel Timponi \\ Vinicius Durval Dorne ${ }^{5}$
}

\begin{abstract}
Resumo
O artigo apresenta proposta do Ciclo de debates "Discurso jornalístico em tempos de pandemia", realizado no segundo semestre de 2020 como atividade extensionista de ensino remoto para divulgação científica e discussões acerca das interfaces das produções, circulações e apropriações dos discursos jornalísticos sobre a COVID-19. O objetivo é aprofundar a temática por meio do debate acadêmico e da troca com pesquisadores atuantes em Instituições de Ensino Superior (IES). Além disso, desenvolver uma metodologia baseada em interáreas de atuação, de forma a realizar a combinação da circulação transmídia das produções do jornalismo e o consequente processo de apropriação das mensagens em comentários nas mídias sociais, com a perspectiva metodológica da análise discursiva, a partir dos estudos da escola francesa.
\end{abstract}

Palavras-chave: discurso jornalístico; mídias sociais; COVID-19.

\footnotetext{
Abstract

The article brings as a proposal the Cycle of Journalistic Discourse in Times of Pandemic, in the second semester of 2020, as an extension activity of remote education for the discussion and dissemination about interfaces of productions, circulations and appropriations of journalistic discourses about COVID-19. The purpose of this action is to deepen the theme in academic discourse and exchangings with various researchers of Higher Education Institutions (HEI). Besides that, the aim is to develop a methodology in order to combine the transmedia circulation of journalism productions and the consequent

1 Professora na Faculdade de Comunicação da Universidade Federal da Bahia. ivaniseha@gmail.com

2 Graduanda do Curso de Jornalismo da Faculdade de Educação da Universidade Federal de Uberlândia. karolina@ufu.br

3 Professora associada do Curso de Jornalismo da Faculdade de Educação da Universidade Federal de Uberlândia. mirnatonus@gmail.com

4 Professora adjunta do Curso de Jornalismo da Faculdade de Educação da Universidade

Federal de Uberlândia. raquel.timponi@gmail.com

5 Professor adjunto do Curso de Jornalismo da Faculdade de Educação da Universidade

Federal de Uberlândia. dorne.vinicius@gmail.com
} 


\section{VOZES \\ ¿DIÁl DCo}

Itajaí, V. 19, n.02, jul-dez 2020

appropriation process of messages by social media users comments, with the perspective of discursive analysis, from the french school studies.

Key words: jornalistic discourse; social media; COVID-19.

\section{Introdução}

O contexto de pandemia, que afeta o mundo todo desde março de 2020, modificou diversos aspectos da vida humana, em especial aqueles que envolvem a comunicação. Situações que até então eram excepcionais ou esporádicas, como vídeo e webconferências, tornaram-se a principal atividade de profissionais e pesquisadores da área, para além de docentes e discentes que se viram em meio a atividades remotas como aulas, provas, apresentações de trabalho, entre outras. Neste sentido, a reportagem, publicada na Revista Exame no dia 23 de abril de 2020, sob o título "Na Quarentena, o mundo virou uma live", de autoria de Lucas Agrela, Maria Eduarda Cury e Tamires Vitorio, revelou que a pandemia ocasionou a ampliação exponencial das transmissões de shows e das chamadas lives. Segundo dados apurados e obtidos com a equipe do YouTube, "as buscas por conteúdo ao vivo cresceram 4900\% no Brasil no período da quarentena" (AGRELA et al., 2020, s.p). Desse modo, com a necessidade de divulgação do trabalho, mais que obrigação, a possibilidade de compartilhar discussões teórico-conceituais e resultados com outros pesquisadores, docentes, discentes e profissionais tornou-se oportunidade.

Tal contexto desencadeou a produção de inúmeros materiais jornalísticos sobre o tema (números da doença, cuidados necessários, pesquisas em curso por laboratórios e instituições, o comportamento social frente ao isolamento, desenvolvimento de vacinas etc.), bem como a proliferação de posts, comentários e desinformação por parte dos usuários em mídias sociais, aplicativos de trocas de mensagens instantâneas.

Foi considerando este cenário que se desenvolveu a proposta do Ciclo de Debates "Discurso jornalístico e política em tempos de pandemia", realizado entre agosto e dezembro de 2020, no âmbito das Atividades Acadêmicas Remotas Emergenciais (AARE), desenvolvidas para Instituições Federais de Ensino Superior (IFES), em que atuam ou atuaram os autores deste artigo, sob forma seja de coordenação, seja de colaboração, enquanto atividade extensionista ${ }^{6}$ que desempenha papel importante no desenvolvimento e na comunicação da pesquisa conduzida por eles, desde 2019.

\footnotetext{
${ }^{6}$ A atividade está devidamente registrada na Pró-Reitoria de Extensão, Cultura e Assuntos Estudantis (Proex), enquanto Projeto - Ação Processual e contínua de caráter educativo, social, cultural, científico ou tecnológico, com objetivo específico e prazo determinado.
} 


\section{VOZES \\ ¿DIÁl DCo}

Itajaí, V. 19, n.02, jul-dez 2020

Neste texto, busca-se refletir sobre a realização do referido ciclo de debates, considerando: a proposta como um todo, incluindo seus objetivos, justificativa e embasamento teórico, no sentido da comunicação da pesquisa desenvolvida; temas e abordagens sugeridos, sendo alguns já abordados em etapas, e o envolvimento do público das discussões; e desdobramentos das possibilidades de análises e de relação para a proposta de desenvolvimento de metodologias integradas para o complexo objeto que a pesquisa abrange.

\section{Comunicação da pesquisa por meio da extensão}

A atividade de que trata este artigo foi concebida no sentido de compreender as práticas discursivas políticas e o desvirtuamento da informação inicial divulgada em perfis de veículos jornalísticos nas mídias digitais sobre a temática da COVID-19.

Compreende-se que o jornalismo ganhou um papel fundamental desde o surgimento da pandemia, na forma seja de reportar, seja de prestar serviços de informação sobre saúde pública à sociedade. Ao mesmo tempo, os profissionais têm a difícil missão de separar conteúdos enganosos da informação que pode ser útil para a vida em sociedade, em momentos de isolamento social.

A proposta faz parte de uma pesquisa de intergrupo, denominada "Práticas discursivas nas mídias sociais: por um mapeamento entre os sentidos de produtores jornalísticos e dos usuários da rede”, aprovada no edital n. 001/2018 - Demanda Universal da Fundação de Amparo à Pesquisa do Estado de Minas Gerais (FAPEMIG), e composta pelos professores proponentes da atividade. O objetivo da pesquisa em questão é realizar análises dos discursos polêmicos recorrentes nas práticas jornalísticas e conversações, estabelecidas nos sites de redes sociais $(\mathrm{SRS})^{7}$ e em ambientes digitais, de modo a compreender os enunciados oriundos de produtores jornalísticos e de usuários das redes.

A ideia apropriada da pesquisa para o ciclo de debates é, a cada encontro, a partir de recortes de acontecimentos jornalísticos sobre a pandemia e cases, tratar sobre como esses discursos foram elaborados, a partir de quais estratégias discursivas e instrumentos e, nesse ínterim, quais sentidos foram colocados em circulação. A justificativa da ação, além de fazer parte da pesquisa em desenvolvimento, está no alcance do público, tendo em vista que o assunto está em curso, o que é favorável para incitar interesse para debates sobre acontecimentos recentes no campo midiático.

Além disso, entende-se ser esta uma forma adequada de contribuir com a divulgação científica e produção de conhecimento, bem como sinalização de rumos relacionados ao fazer jornalístico, considerando os fatores dificultadores da profissão durante esse momento de enclausuramento. Neste sentido, o projeto de pesquisa foi

\footnotetext{
7 Utiliza-se mídias sociais como sinônimo.
} 


\section{VOZES: \\ \&DIÁl OCO}

Itajaí, V. 19, n.02, jul-dez 2020

apresentado no primeiro encontro do ciclo de debates, a fim de evidenciar e explicar a problemática, o que já foi realizado, as metodologias envolvidas - a abordagem multimetodológica se estabelece enquanto tentativa de responder a um problema que uma teoria/método, isoladamente, parece não atender -, o corpus - veículos independentes, originalmente - Apontou-se para a readequação da pesquisa a um objeto/problema do presente, qual seja, a pandemia de COVID-19.

Assim, como objetivo, o ciclo tem por vias refletir como a informação é abordada nesse cenário de pandemia, seja pela mídia jornalística, seja por meio de conteúdos produzidos por demais agentes sociais, a fim de responder a questionamentos referentes, por exemplo, aos efeitos da divulgação de conteúdos enganosos na sociedade ou ao emprego da política no setor da saúde, bem como sua relação com interesses econômicos.

Quanto à estrutura, a atividade se compõe de cinco encontros, programados para agosto a dezembro de $2020^{8}$, com duas horas de duração cada e periodicidade mensal, em duas etapas de AARE no período especial conforme estabelecido pela instituição, sendo dois temas na primeira etapa e três na segunda. Os encontros são realizados por meio da plataforma Jitsi Meet, tendo como alternativa à transmissão YouTube com StreamYard".

\section{Temas em debate}

Os temas tratados a seguir foram pensados no sentido de ampliar o público, considerando que não apenas docentes e discentes da IFES em questão poderiam interessar-se, mas, também, pesquisadores e profissionais da área da comunicação de outras localidades, à medida que a conferência via web permite essa ampliação da distribuição geográfica dos participantes ${ }^{10}$.

\section{Política e desvirtuamento da informação}

O tema de abertura do ciclo de debates foi "Influência política no desvirtuamento da informação jornalística sobre a COVID-19”, no qual foi abordado o fenômeno que ficou conhecido como "infodemia" (SORRIBES, 2020, p. 98), de forma a debater sobre

\footnotetext{
${ }^{8}$ Quando da submissão deste artigo, haviam sido realizados três encontros.

${ }^{9}$ Em resolução específica sobre as AARE, a instituição indicou que os planos de oferta das atividades deveriam explicitar as plataformas de Tecnologia da Informação (TI) e softwares. 10 Durante os encontros, a média de público foi de 40 a 50 pessoas, advindas de diferentes instituições e estados e em distintos níveis de formação, considerando desde estudantes de graduação a pesquisadores, pós-graduandos (mestres e doutores) com estudos em temáticas afins, profissionais e professores.
} 


\section{VOZES $_{\text {\&IÁLORO }}^{\mid}$}

Itajaí, V. 19, n.02, jul-dez 2020

tal desvirtuamento com o intuito político de disseminação de práticas contrárias ao isolamento social, a partir dos exemplos do Brasil e dos EUA.

Em um comparativo da desinformação sobre o tema da COVID-19 com o número de aumento de casos dos dois epicentros da pandemia, como estudo de caso foi dado destaque ao levantamento realizado pelo Projeto Coronavírus Fact Checking Alliance, do Institute Poynter $^{11}$ - composto por mais de 100 organizações em mais de 74 países, desmascarando conteúdos falsos em 43 idiomas diferentes a partir de afirmações, vídeos, fotos, áudios - e da Rede Internacional de Fact Checking para compreender os instrumentos mais comuns utilizados na produção e propagação da desinformação no tema do COVID-19. Discutiu-se, a partir de tais fontes, sobre como detectar esses conteúdos falsos, à medida que os bancos de dados mudam diariamente e pode haver informações desatualizadas. A relevância do contexto também foi salientada no debate, considerando que cada país tem características climáticas, geográficas e populacionais diferentes.

Um dos questionamentos apresentados sobre o tema em questão referiu-se ao que se considera como vulnerabilidade em situações de compartilhamento da desinformação. Entende-se que há mecanismos que impulsionam a circulação de mentiras no contexto atual, tais como: a) falta de dados, pois tudo o que sabemos sobre coronavírus é muito novo, menos de um ano; b) mudanças constantes nos bancos de dados, à medida que não somente os verificadores, mas as pessoas também ainda estão aprendendo a lidar com informações sobre a pandemia, o que pode criar um solo fértil para a desinformação; c) cenário de pânico, o que contribui para espalhar mentiras e boatos; d) desinformação sobre saúde relacionada com desinformação política, o que gera polarização, ou seja, parte da desinformação sobre saúde é compartilhada com boa intenção - curas falsas, medidas preventivas equivocadas -, pois as pessoas compartilham com amigos e familiares com os quais se importam, tomando tais conteúdos como úteis, e parte é composta por conteúdos maliciosos, para deturpar a informação e se transfere para o âmbito político; e) uso político da pandemia para propagar uma ideologia.

Esses elementos foram debatidos a partir da coleta de dados realizada no projeto acima mencionado, em material extraído do vídeo de entrevista que a jornalista Maryn McKenna realizou com a coordenadora do grupo na América Latina, Cristina Tardáguila, para o curso "Jornalismo na Pandemia: cobertura do COVID-19 agora e no futuro", Massive Open Online Course (MOOC) do Knight Center of Journalism in the America, realizado em maio de 2020 em parceria com Organização das Nações Unidas (ONU) e Organização Mundial de Saúde (OMS).

Destaca-se, no último elemento, a política associada à desinformação, com destaque para a situação brasileira diante de um posicionamento que tem promovido ideias de abertura, contrárias ao isolamento social preconizado pela OMS e colocando dualismos

"O projeto está disponível em https://www.poynter.org/coronavirusfactsalliance/. 


\section{VOZES $_{\text {\&IÁLORO }}^{\mid}$}

Itajaí, V. 19, n.02, jul-dez 2020

entre, por exemplo, economia e saúde. Neste sentido, o Brasil, poucos meses após o início da pandemia, chegou a um dos países com maior taxa de contágio do mundo, segundo estudo divulgado pelo Imperial College of London (2020). Em um contexto como esse, parece haver certa dificuldade em se mostrarem dados de verificação com vistas a esclarecer os sujeitos e fazer com que esses se interessem.

Quando se diz que essa informação dita pelo político é falsa, as pessoas entendem que estamos atacando o político ideologicamente e começam a reproduzir pensamentos construídos previamente de ideologia e que não estão relacionados ao conteúdo central, inicial (TARDAGUILA, 2020).

Tomando como exemplos os veículos Jornalistas Livres e O Antagonista, objetos da pesquisa inicial desenvolvida pelos autores desde 2018, chamam atenção as diferentes formas de abordar o assunto pandemia. Enquanto o primeiro realiza produções mais analíticas, contextualizadas, comportamentais e, em sua página no Facebook, publica crítica política, charges e chamadas para manifestos, prioritariamente, o segundo opta por matérias de cunho político e com recorte em representantes políticos relacionados ao tema da COVID-19. Buscou-se, a partir dessa comparação, tecer uma relação com a área da pesquisa do grupo sobre as práticas discursivas nas mídias sociais para compreender o fenômeno da informação polarizada e sua relação com a desinformação.

Um dos exemplos tratados no encontro foi a desinformação que circulou sobre a vacina da Covid-19 e sua relação com a cientista e pesquisadora de Oxford Sarah Gilbert. O post inverídico, disseminado pela página do Instagram @enseñame_de_ciéncia, com mais de 53,2 mil compartilhamentos entre Instagram e Facebook, demonstrou a força da disseminação de uma desinformação nas redes digitais. A falsa informação propagada, de que a cientista da equipe desenvolvedora da vacina da universidade de Oxford "havia testado em seus filhos trigêmeos, entre os cinco primeiros voluntários, como forma a comprovar sua eficácia”, foi retirada do contexto. Conforme veículos de checagem brasileiros e internacionais, esses elementos eram falsos - o fato curioso de a pesquisadora de Oxford ter três filhos gêmeos foi divulgado em uma das reportagens no site da Bloomberg sobre a equipe que trabalhou no desenvolvimento da vacina e levou à apropriação indevida da informação, de forma a relacionar com o fato do teste da vacina. Apesar de os filhos terem tomado a vacina voluntariamente, entre muitos outros que se predispuseram, isso fez com que a informação fosse destacada e retirada do contexto.

Neste sentido, assim como esse caso, muitas desinformações relacionadas à saúde e ao vírus passaram a ser instrumentos políticos para polarizações e demarcação de oposições de falas, a exemplo, o movimento antivacina e pró-vacina. 


\section{VOZES $_{\text {\&IÁLORO }}^{\mid}$}

Itajaí, V. 19, n.02, jul-dez 2020

\section{Estratégias discursivas}

O tema do segundo encontro tratou de "Estratégias discursivas na construção de notícias falsas sobre a pandemia de COVID-19". A partir do campo de estudos da Análise do Discurso (AD) de linha francesa ${ }^{12}$, debateu-se, a partir de exemplos da mídia, como os discursos, enquanto práticas sociais: a) constroem a realidade e formas de interpretá-la; b) permeiam os modos de vida e os regimes de sociabilidade; c) interferem na produção de pensamento e de autonomia dos sujeitos; d) deslocam os sentidos para outros campos como estratégia de veridicção; e) produzem saberes e o exercício de poder na sociedade.

O encontro partiu do ponto em que se questiona como a disseminação de conteúdos enganosos pode ter consequência na vida pessoal em tempos de pandemia. A relação foi estabelecida pela coleta de notícias em consequência de divulgação de informações falsas sobre a COVID-19 em perfis de mídias sociais de veículos jornalísticos. Refletiu-se como o discurso estabelece a mediação entre os sujeitos e a realidade, de tal modo que é por meio da linguagem que os sujeitos se constituem e (re)significam o mundo.

Com o advento da pandemia de COVID-19 e o maior uso das tecnologias de comunicação, o meio virtual tornou-se uma das principais fontes de recebimento e compartilhamento de informações, superando o uso da televisão, segundo levantamento da Reuters Digital News Report. Com isso, o fluxo de circulação discursiva se intensifica, impactando a produção de sentido sobre a doença. Todavia, as análises revelam que mais informação não significa, necessariamente, informação de qualidade. Assim, foi preciso compreender como, no percurso de circulação da notícia, ocorrem distorções e (re)construções de sentidos a partir dos diferentes modos de apropriação e compartilhamento das informações.

Para tratar dos tópicos indicados acima, considerou-se importante refletir, inicialmente, sobre como a AD se diferencia da Análise de Conteúdo (AC) - comumente realizada para interpretação dos fenômenos que ocorrem nas mídias sociais -, definir o que é discurso e tratar de aspectos relacionados à sua constituição, quais sejam, as etapas de produção, circulação e recepção de sentidos, envolvendo linguagem, sujeito, realidade.

À medida que a $\mathrm{AD}$ é parte primordial da pesquisa em desenvolvimento, foram abordados os enunciados advindos de mídias sociais de veículos de comunicação, as estratégias discursivas e uso de elementos de credibilidade, bem como tais estratégias na construção da notícia e a desinformação, de forma a reunir diferentes metodologias para análise de um fenômeno complexo.

\footnotetext{
${ }^{12} \mathrm{O}$ discurso neste trabalho é compreendido como uma forma de interpretação e produção da realidade, materializado em textos, imagens estáticas ou audiovisuais, por exemplo. Entende-se que notícias são construções discursivas.
} 


\section{VOZES: \\ ¿DIÁl DRO}

Itajaí, V. 19, n.02, jul-dez 2020

O debate centrou-se nas estratégias discursivas de veículos diversos - O Estado de S. Paulo, Folha de S. Paulo, Jornal do Commercio, Meia Hora, - em seus sites e respectivos perfis em mídias sociais, especificamente Twitter, a partir de fotografia registrada em praia lotada no Rio de Janeiro em dia de sol.

A imagem de origem do veículo Estadão foi alvo de críticas de alguns influenciadores digitais, como o perfil de Guilherme Fiuza - @GFiuza_Oficial, na data da redação deste artigo, com 606 mil seguidores -, que chegou a insinuar que a imagem era falsa, gerando reações em rede e uma resposta do veículo e das agências de checagem de que a fotografia era real (Figura 1), e o comentário em post no Twitter da jornalista Tatiana Vasconcellos - @tavasconcellos, com 87 mil seguidores - que levou a discussão para outra polarização entre a possibilidade de sair por lazer e por necessidade de trabalho, gerando polêmica no Twitter e disseminação da produção e circulação em diferentes veículos de mídia (Figura 2).

Assim, a imagem recirculada nos referidos veículos, levou a um confronto com sujeitos que tentaram desconstruir tal discurso por meio da sugestão de que as imagens haviam sido capturadas em outro momento, o que demandou de agências de checagem a verificação sobre a veracidade.

Figura 1: Postagem de Guilherme Fiuza questionando veracidade da fotografia

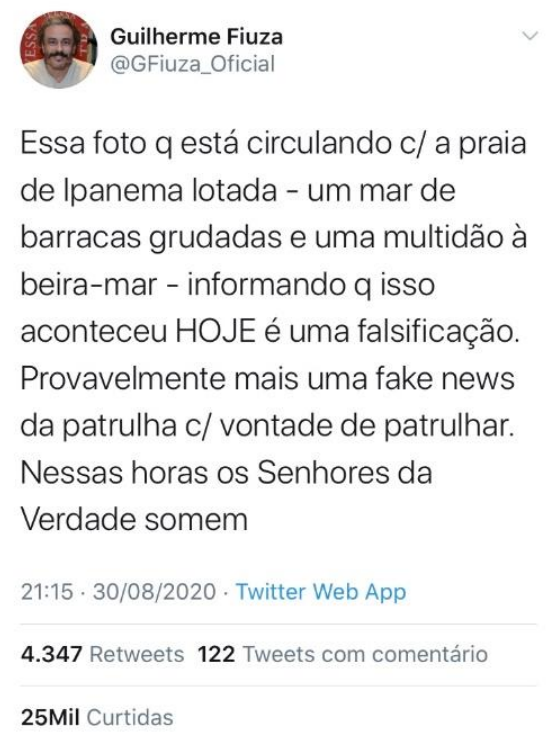

Fonte: Perfil no Twitter de @GFiuza_Oficial, publicação do dia 30/08/2020 


\section{VOZES}

Itajaí, V. 19, n.02, jul-dez 2020

Figura 2: Postagem de Tatiana Vasconcellos com polêmica sobre lazer e necessidade

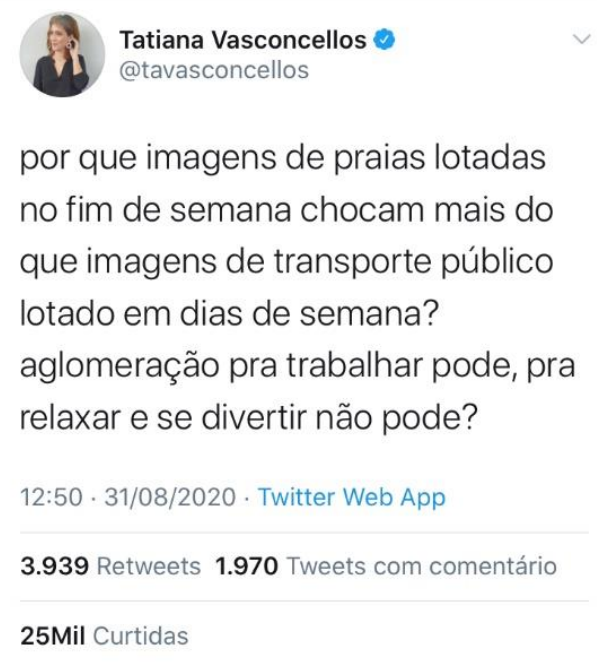

Fonte: Perfil no Twitter de @tavasconcellos, publicação do dia 31/08/2020

Desta forma, refletiu-se sobre como a produção de sentidos é estabelecida no jogo/relação entre os sujeitos, não condicionada, somente, ao sujeito produtor de enunciados; os sentidos são (re)arranjados, negociados na circulação dos discursos, nas leituras e interpretações por parte dos sujeitos. Buscou-se observar como o acontecimento da presença de pessoas nas praias do Rio de Janeiro foi discursivizada, seja pelos agentes da mídia, seja pelos usuários em mídias sociais: como, no trabalho com a linguagem (logo, com o simbólico), esse fato foi construído discursivamente. A partir do gesto de análise, questionou-se como os discursos constroem a realidade, como os sentidos podem se reconfigurar a partir do lugar que os sujeitos ocupam no discurso, como a verdade é um produto do discurso, inscrita em regimes de verdade de uma dada época, de um dado campo.

A publicação se estendeu para ambientes políticos brasileiros, como verificado no Senado Notícias, em matéria na qual senadores se posicionaram com preocupação diante da aglomeração nas praias, contrariando as medidas sugeridas pela OMS. Frente a isso, refletiu-se sobre como todo discurso atende e ampara o exercício de poderes na sociedade, sendo arena de lutas e disputadas, lugar de conflitos, de permanências, mas também de deslocamentos.

\section{Circulação e construção de discursos}

O terceiro tema, por sua vez, abrangeu "A COVID-19 construída discursivamente pela grande mídia: parte 1 (os produtores)”, com a pretensão de instigar o debate a respeito 


\section{VOZES $_{\& \text { DIÁLORO }}^{\downarrow}$}

Itajaí, V. 19, n.02, jul-dez 2020

das formas sob as quais ocorre o surgimento de notícias sobre a COVID-19, desde sua origem, por produtores midiáticos, via agências de notícias e redações, à publicação e circulação da informação. O objetivo era percorrer o caminho de disseminação/fluxo da informação a partir de veículos da grande mídia, por meio de uma análise transmidiática da notícia, para compreender como os sentidos produzidos pela mídia são (re)arranjados por diferentes canais e linhas editoriais.

Destaca-se, nesse sentido, a veiculação de enunciados em perfis de veículos de comunicação em mídias sociais, nas quais os produtores jornalísticos interagem e se pretende engajar o público, que se mostra, ao mesmo tempo, consumidor e produtor de informações e conteúdos.

Partindo da dispersão textual em diferentes veículos e da construção complementar da informação em diversas plataformas, em uma lógica que se transmuta do papel de gatekeeper dos veículos à prática do gatewatching (BRUNS, 2011), a circulação foi analisada a partir de gráfico adaptado de Ishida e Collaço (2012), que o desenvolveram para análise de narrativas transmídia, mas aplicadas ao jornalismo, na qual se observam lacunas dos produtos midiáticos e elementos identificadores, reconhecidos pelo público, e intensificadores, voltados à participação e ao engajamento. $\mathrm{O}$ gráfico, conforme esses autores, representa o universo narrativo, no qual se insere um espaço de construção da narrativa transmídia, mediante indicativos das mídias e histórias envolvidas, e, também, linhas de histórias, com delimitação temporal das mídias e seu posicionamento no universo narrativo, além de cruzamentos de mídia, pontos de origem ou intersecção de partes da história em cada mídia.

A fim de visualizar o caminho traçado pelos produtores de informação sob a perspectiva transmidiática, aplicou-se o método para entender a circulação das notícias a partir de publicações da Fundação Oswaldo Cruz (Fiocruz), sendo uma delas o Manual sobre Biossegurança para Reabertura de Escolas no Contexto da COVID-19 ${ }^{13}$. Sobre esse material, circularam notícias em diversos formatos e mídias, no Portal Fiocruz, no site da Escola Politécnica de Saúde Joaquim Venâncio (EPSJV) também pertencente à Fiocruz, no perfil da EPSJV e no perfil oficial da Fiocruz no Facebook, no grupo Fiocruz nessa mesma mídia social, em sites de notícias, em programas de TV, na Agência Brasil, em sites institucionais, gerando até mesmo um post na Sociedade Brasileira de Pediatria (SBP). Interessante observar como o fato de circular por veículos como o site da Associação Brasileira de Pediatria tornou-se notícia publicada pelo perfil da EPSJV no grupo Fiocruz, demonstrando a recirculação de um conteúdo, ainda que modificado, para mídias próprias da Fundação.

\footnotetext{
${ }^{13}$ O manual foi elaborado com base no "plano de contingência e biossegurança para o retorno às atividades de ensino na Escola Politécnica de Saúde Joaquim Venâncio (EPSJV/Fiocruz)" (PEREIRA et al., 2020).
} 


\section{VOZES $_{\text {\&IÁLORO }}^{\mid}$}

Itajaí, V. 19, n.02, jul-dez 2020

Assim, destacou-se a importância da relação entre teorias e métodos, como proposto no projeto de pesquisa dos autores, do qual o Ciclo de Debates é um dos desdobramentos. Não raro, os estudos discursivos se centram nas etapas de produção e recepção dos sentidos, e em menor grau na etapa de circulação. Da mesma maneira, a análise transmidiática possibilita a leitura do caminho da informação, sem o intuito de refletir sobre como esse processo desempenha papel preponderante na produção de discursos, na circulação de sentidos. Desta forma, aliando as potencialidades e o alcance de cada método, propõe-se observar como a análise transmidiática possibilita compreender a circulação dos enunciados nas mídias para, de porte deste conhecimento, realizar o gesto de análise - descrição e interpretação - por meio da AD.

Destaca-se que tal análise pode ser aplicada a uma ampla gama de produções jornalísticas, a fim de se entender os caminhos e os processos de transmidiação a partir delas, considerando, para além do que veiculam os produtores, a expansão da narrativa com a participação de outros veículos e também do público, por meio de comentários e outras publicações, o que foi pensando para o quarto encontro.

\section{Comentários, um caminho peculiar}

Em continuidade do processo de ressignificação e apropriação das mensagens dos veículos pelos usuários das redes, como em um "telefone sem fio", o caminho discursivo da COVID-19 chega aos comentários das mídias sociais e se reverbera pela produção de sentidos outros. Esse é o tema do quarto e penúltimo encontro da atividade, com vistas a analisar como se altera a produção de sentido da mensagem inicial por parte do usuário produser - produtor e usuário da informação, simultaneamente (BRUNS, 2008).

A partir de uma notícia emblemática sobre a COVID-19, debate-se sobre como seria o caminho da notícia em sua apropriação pelo público até a disseminação de informações em diferentes comentários realizados pelos usuários e outros atores das redes digitais, como a presença dos bots e de perfis falsos, na promoção do caos nas mídias sociais e na distorção do conteúdo inicial da mensagem.

Como forma de selecionar a diversidade discursiva produzida nos comentários e de temáticas, utiliza-se a web semântica, pensando-se em uma lógica de seleção quanti/qualitativa da informação. A ideia da web semântica é compreender como a máquina/computador pode cooperar de modo eficaz na análise da produção discursiva e como pode ser usada na interpretação de conteúdos tão diversos como os comentários realizados nos perfis de veículos nas mídias sociais. Berners-Lee et al. (2001) propuseram o modelo de web semântica, com a proposta de definir como a web poderia auxiliar o usuário a realizar tarefas cotidianas, assessorado por mecanismos computacionais, chamados de agentes. 


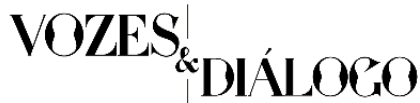

Itajaí, V. 19, n.02, jul-dez 2020

Apropriando-se dessa relação, pode-se pensar a web semântica em estudos voltados para a análise dos temas e debates advindos de diferentes lugares, através de ferramentas de busca e monitoramento ou ainda pela seleção da informação dos posts de mídias sociais por palavras-chave, como é o caso da atual pesquisa. Nesse processo, selecionam-se os posts mais engajados; em seguida, realiza-se a seleção dos comentários mais relevantes desses posts; para, a partir da classificação e categorização das temáticas dos comentários realizar inferências e interpretação de elementos desses dados (RECUERO, 2018). Por fim, é realizada a análise do processo discursivo do emissor e dos comentários e como essas falas atuam e representam o desvirtuamento da informação do enunciado central, do intuito inicial da notícia veiculada.

Portanto, este quarto encontro busca compreender como, na contemporaneidade, se constroem efeitos de verdade não somente pela mídia, mas também pelos usuários das mídias sociais. A verdade, sobremaneira, é um produto de discurso, agenciada por sujeitos ou atores - não humanos que realizam ações e postagens por padrão de comportamentos captados pelos algoritmos e imersos na programação -, produzindo o exercício de determinados poderes no corpo social - e em práticas de sociabilidade nessas mídias sociais. Assim, ocorre uma disputa pela legitimação da verdade por sujeitos, instituições, e outros actantes (PRIMO, 2013). Faz-se necessário, então, refletir sobre como as estratégias discursivas constituem os discursos que circulam, como atuam na produção de enunciados que funcionam como efeitos de verdade para/pelos sujeitos ou programações de determinados comportamentos e padrões de fala.

\section{Entrecruzamento metodológico}

O último tema - "Discurso de ódio e violência nas redes digitais: três caminhos para se compreender a produção discursiva sobre a COVID-19" - foi pensado no sentido de se analisar, no hábito corrente de consumo da informação, como os sujeitos tendem a reproduzir os discursos pré-estabelecidos - de sentidos estabilizados e naturalizados -, em enunciados que reforçam violência e agressão. A partir da proposta de compreensão de três metodologias entrecruzadas - a transmidiática (com vistas a detectar o circuito de disseminação da informação polarizada), a web semântica (para levantar regularidades discursivas), e a AD (para analisar as estratégias e o funcionamento dos enunciados) -, mapeiam-se os discursos enquanto práticas sociais, levando em consideração casos sobre discurso de ódio advindos de notícias sobre a COVID-19 nos principais perfis de mídias sociais de veículos jornalísticos.

Entende-se que o caminho proposto na sequência de temas exposta permite certo aprofundamento na análise de informações sobre a COVID-19 em publicações digitais e mídias sociais, ultrapassando os limites do conteúdo. 


\section{Desdobramentos das possibilidades de análises}

Como resultado dos debates até então realizados, reitera-se a potencial contribuição das metodologias para análises multidimensionais de produções jornalísticas neste contexto pandêmico que, a princípio, não revela estimativa de quando irá terminar.

Entender como as informações circulam em um universo narrativo transmidiático, no qual pelo menos duas mídias contam parte de uma história (JENKINS, 2010), e, ao mesmo tempo, como os discursos são construídos nessa circulação e recirculação indica uma proposta metodológica inovadora e com significativas possibilidades de aplicação a outros contextos.

Destarte, a realização de debates em projetos de extensão por meio remoto tem possibilitado a divulgação dos exercícios de entrecruzamento de teorias e métodos para além dos periódicos e eventos acadêmicos-científicos, centrados nos pares, estimulando o - importante e necessário - diálogo e a produção do conhecimento com a comunidade. A partir do ciclo ora apresentado, delineia-se a perspectiva de produções futuras, que explorem detalhadamente cada um dos temas que o compõem.

\section{Referências bibliográficas}

AGRELA, Lucas; CURY, Maria Eduarda; VITORIO, Tamires. Na Quarentena, o mundo virou uma live. Exame. Disponível em: https://exame.com/revista-exame/omundo-e-uma-live/. Acesso em: 13 ago. 2020.

BERNERS-LEE, T.; HENDLER, J.; LASSILA, O. The semantic web. Scientific American, v. 284, n. 5, p. 28-37, 2001.

BRUNS, Axel. Blogs, Wikipedia, Second Life and beyond: from production to produsage. New York: Peter Lang, 2008. Disponível em <https://encurtador.com.br/hEFGY> . Acesso em: 10 set. 2020.

. Gatekeeping, Gatewatching, realimentação em tempo real: novos desafios para o Jornalismo. Brazilian Journalism Research, v. 7, n. 2, p. 1-22. abril de 2011. Disponível em <https://bjr.sbpjor.org.br/bjr/article/view/342〉 . Acesso em: 26 set. 2020. 


\section{VOZES $_{\text {\&IÁLORO }}^{\mid}$}

Itajaí, V. 19, n.02, jul-dez 2020

IMPERIAL COLLEGE LONDON. COVID-19 - updates and guidance. Londres, 2020. Disponível em: https://www.imperial.ac.uk/about/covid-19/ Acesso em: 13 jul. 2020

ISHIDA, Gabriel; COLLAÇO, Fernando. Caminhos para Metodologia de Análise em Transmídia. Apresentação Slideshare. II Fórum Transmídia. São Paulo. 2012. Disponível em http://pt.slideshare.net/gabrielishida/metodologia-e-grfico-transmdia-iifrum-transmIdia-2012. Acesso em: 15 out. 2020.

NEWMAN, Nic Newman; FLETCHER, Richard; SCHULZ, Anne; ANDI, Simge; NIELSEN, Rasmus Kleis. Digital News Report 2020. Reuters Institute for the Study of Journalism. Londres, 2020. Disponível em: https://www.digitalnewsreport.org/. Acesso em: 20 out. 2020.

JENKINS, Henry. Cultura da convergência. São Paulo: Aleph, 2010.

PEREIRA, Ingrid D'avilla Freire; CORBO, Anamaria D'Andrea; DE PAULA, Tainah Silva Galdino; MENDONÇA, Flávia Coelho Ribeiro; VALLE, Silvio. Manual sobre biossegurança para reabertura de escolas no contexto da COVID-19. Rio de Janeiro: $\begin{array}{llllll}\text { EPSJV/Fiocruz, } & 13 & \text { jul. } & 2020 . & \text { Disponível em }\end{array}$ http://www.epsjv.fiocruz.br/sites/default/files/manual_reabertura.pdf. Acesso em: 29 out. 2020 .

PRIMO, Alex. Interações mediadas e remediadas: controvérsias entre as utopias da cibercultura e a grande indústria midiática. In: PRIMO, Alex (org.). Interações em rede. Porto Alegre: Sulina, 2013. p. 13-32. Disponível em 〈https://encurtador.com.br/dquH6>. Acesso em: 9 set. 2020.

RECUERO, Raquel. Estudando discursos em mídia social: uma proposta metodológica. In: SILVA, Tarcízio. Estudando cultura e comunicação com mídias sociais. Brasília: Ibpad, 2018.

SORRIBES, Carles Pont. Infodemia, el virus mediado. In: Gutiérrez-Rubí, Antoni; SORRIBES, Carles Pont (Coord.). Comunicación política en tiempos de Coronavirus. Barcelona: Cátedra Ideograma-UPF de Comunicación Política y Democracia, 2020.

Disponível em https://www.upf.edu/documents/220602201/233560922/Definitiu+Comunicaci\%C3\%B3n +Coronavirus/1c1d3def-34ae-fe5d-0019-ef40c936b0e3. Acesso em: 29 out. 2020. 


\section{VOZES $_{\text {\&IÁLORO }}^{\mid}$}

Itajaí, V. 19, n.02, jul-dez 2020

TARDAGUILA, Cristina. Jornalismo na Pandemia: cobertura do COVID-19 agora e no futuro. Entrevista concedida a Maryn McKenna. Knight Center Course. Youtube. 10 maio 2020.2 Disponível em: https://www.voutube.com/watch?v=IM7haZvQ9JM\&feature=youtu.be\&app=desktop. Acesso em: 30 out. 2020. 